Hydrology and Earth System Sciences, 8(6), 1118-1128 (2004) C EGU

\title{
Relationships between the El-Niño Southern Oscillation and spate flows in southern Africa and Australia
}

\author{
Julian P. Whiting ${ }^{1}$, Martin F. Lambert ${ }^{1}$, Andrew V. Metcalfe ${ }^{2}$, Peter T. Adamson ${ }^{2}$, \\ Stewart W. Franks ${ }^{3}$ and George Kuczera ${ }^{3}$ \\ ${ }^{1}$ Centre for Applied Modelling in Water Engineering, School of Civil and Environmental Engineering, University of Adelaide, Adelaide 5005, Australia \\ ${ }^{2}$ School of Mathematical Sciences, University of Adelaide, Adelaide 5005, Australia \\ ${ }^{3}$ School of Engineering, University of Newcastle, Callaghan 2308, Australia \\ Email for corresponding author: jwhiting@civeng.adelaide.edu.au
}

\begin{abstract}
The flow records of arid zone rivers are characterised by a high degree of seasonal variability, being dominated by long periods of very low or zero flow. Discrete flow events in these rivers are influenced by aseasonal factors such as global climate forcings. The atmospheric circulations of the El-Niño Southern Oscillation (ENSO) have been shown to influence climate regimes across many parts of the world. Strong teleconnections between changing ENSO regimes and discharges are likely to be observed in highly variable arid zones. In this paper, the influence of ENSO mechanisms on the flow records of two arid zone rivers in each of Australia and Southern Africa are identified. ENSO signals, together with multi-decadal variability in their impact as identified through seasonal values of the Interdecadal Pacific Oscillation (IPO) index, are shown to influence both the rate of occurrence and the size of discrete flow episodes in these rivers.
\end{abstract}

Keywords: arid zones, streamflow, spates, climate variability, ENSO, Interdecadal Pacific Oscillation, IPO

\section{Introduction}

The El Niño Southern Oscillation (ENSO) is known to induce climatic variation throughout much of the world. The warming and cooling of equatorial sea-surface waters in the Pacific, known as El Niño and La Niña events, and related changes in air pressures of the South Pacific known as the Southern Oscillation, are part of a global climate system. These large-scale interactions between the ocean and atmospheric circulations are related to global temperature, rainfall and streamflow anomalies (Chiew and McMahon, 2003; Ropelewski and Halpert, 1987; Mason, 1997). Climate indices are a suitable method to assess the ENSO phenomenon, by measuring changes in key atmospheric variables. The Troup Southern Oscillation Index (SOI) (Troup, 1965) is a widely used index, based on the Tahiti-Darwin mean sea level pressure difference across the Pacific Ocean. Furthermore, indices based on changes in sea-surface temperatures in key regions of the Pacific, such as the NINO3 region $\left(5^{\circ} \mathrm{S}\right.$ to $5^{\circ} \mathrm{N}, 90^{\circ} \mathrm{W}$ to $150^{\circ} \mathrm{W}$; Kaplan et al., 1998), have been shown to be accurate indicators of ENSO variability. A more recent development is the Multivariate ENSO Index (MEI) (Wolter and Timlin, 1998). This, being integrated from multiple climate parameters, is less vulnerable to non-ENSO related variability (Kiem and Franks, 2001) because it is able to reflect the complex nature of ocean-atmospheric interactions better than indices based on a single variable. The variables used in the MEI include sea-level pressure, sea surface temperature, zonal and meridional components of the surface wind, surface air temperature and total cloudiness fraction of the sky.

Although ENSO dominates interannual variability in the Pacific climatic regime, there is strong evidence (Power et al., 1999; Salinger et al., 2001) that related climate features also operate on decadal to inter-decadal time scales. This low frequency variability in Pacific sea surface temperatures 
(SSTs) has been termed the Interdecadal Pacific Oscillation (IPO) (Power et al., 1999), and has been shown to modulate strongly the effect of ENSO upon both precipitation variability (Power et al., 1999) and flood risk (Kiem et al., 2003) over Australia. Indices for the IPO have been derived from a number of sources, with the longest series obtained from global SST sets (Folland et al., 1998).

Correlations between ENSO and rainfall occurrence across North America have also been identified (Gershunov and Barnett, 1998), with a multi-decadal variability that is in line with a multi-decadal persistence in North Pacific SSTs that is very similar to the IPO (i.e. Pacific Decadal Oscillation, PDO)(Mantua et al., 1997). Three major phases of the IPO were observed during the 20th century, positive phases between 1921-1944 and 1978-1998 and a sustained negative phase between 1945-1977. In the positive IPO phase, interannual relationships between ENSO and Australian rainfall have been shown to weaken (Power et al., 1999), and teleconnections between SSTs and the SOI in the South West Pacific around New Zealand have been amplified (Salinger et al., 2001).

One of the most important climatic features in the subtropical Southern Hemisphere is the South Pacific Convergence Zone (SPCZ), which delivers rain-bearing cloud bands to eastern and central Australia. Small shifts in the location of the SPCZ can produce large rainfall anomalies (Salinger et al., 2001); alterations in the latitude of the SPCZ due to ENSO events in the Austral summer are an obvious mechanism by which ENSO alters rainfall patterns across the Australian continent. Warm El-Niño events disrupt the propagation of the SPCZ over southern latitudes, causing reduced rainfall across the Australian continent, while cold La Niña periods produce an enhanced southern movement of the zone, which results in higher rainfall. Furthermore, Folland et al. (2002) showed that alterations in the latitude of the SPCZ were related significantly to multi-decadal IPO variability, independent of ENSO influences. During La Niña events that occur in IPO negative epochs, the SPCZ is at its south-western extreme, bringing higher amounts of rain to Australia. As Franks (2004) states, this rationalises the results of Power et al. (1999) who showed the enhancement of La Niña conditions in IPO negative phases. Moreover, this suggests the use of indicator variables for climate categories rather than continuous predictor variables when relating climate variability to hydrological responses.

Multi-decadal modulation in the influence of ENSO upon Indian Ocean sea-surface temperatures has also been characterised, with Landman and Mason (1999) describing a weakening of this ENSO signal since the late 1970s. Anomalous warming and cooling in the Indian Ocean are related, strongly, to seasonal rainfall variability across southern Africa (Jury and Courtney, 1995; Mason, 1997). This region is predominantly arid or semi-arid with high interannual rainfall variability and the influence of ENSO is greatest during the peak rainfall months of December to March (Mason and Jury, 1997). During Pacific El-Niño conditions, the northern Indian Ocean is warmer than normal, playing an important role in the transmission of the El-Niño signal to southern Africa. El Niño events are usually associated with below average rainfall across much of Africa south of about $10^{\circ} \mathrm{S}$ (Mason, 2001); however, the variance in African rainfall totals explained by ENSO is rarely more than about 20\% (Lindesay, 1988). In their review of the relationships between ENSO and rainfall and streamflow records across Australia, Chiew and McMahon (2003) demonstrated that the El Niño-streamflow teleconnection is almost always stronger than the El Niño-rainfall teleconnection.

The present study investigates the role that the ENSO phenomenon has upon flow events in arid zone rivers. The hydrology of arid zones is particularly interesting, being characterised by high seasonal variation in the flow regime with dominant patterns of zero or very low flows. Other factors, including those associated with irregular atmospheric circulations such as ENSO, have been shown to influence flow patterns strongly (Puckridge et al., 2000). Furthermore, the highly variable flow regimes of these regions potentially amplify the ENSO teleconnections observed in the less-extreme flow records of other rivers. Relationships between flooding episodes in arid areas and climate patterns have been investigated (Kotwicki and Allan, 1998), and this study demonstrates that the timing and size of distinct flow events can also be linked closely to ENSO phases. McMahon et al. (1992) highlighted that the most variable flow regimes across the world were located in Australia and southern Africa, and flow records from two rivers in each of these regions are used in this study. Cigizoglu et al. (2002) developed point process models to characterise the discrete flow episodes of two neighbouring arid zone rivers in Africa; however, the roles of large-scale climatic regimes on such episodes were not considered.

\section{Data and working assumptions}

This study examines the flow records from four rivers located within arid zones of the southern hemisphere. The Omatako and Omaruru Rivers are both located in the Kalahari Sandveldt in Namibia, southern Africa, shown in Fig. 1. Annual runoff in this region rarely exceeds $10 \mathrm{~mm}$. Both rivers originate in the high central plateau of the country, with the Omatako flowing north-east as a tributary 


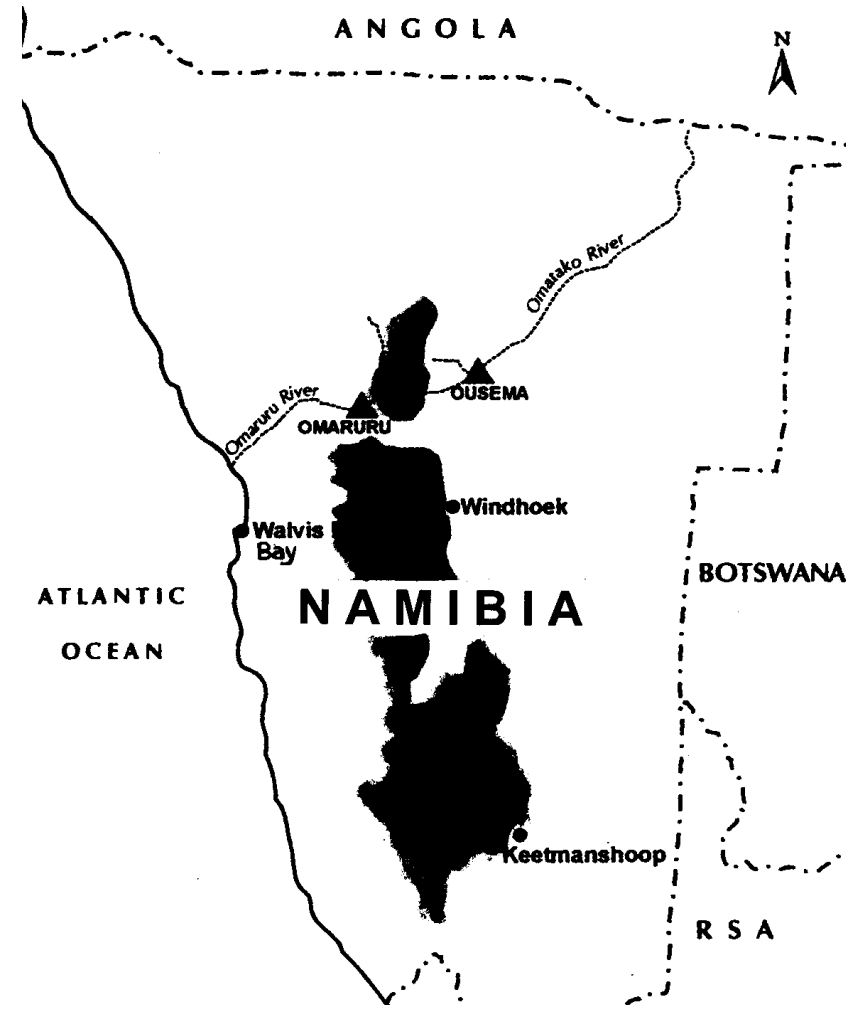

Fig. 1. Locations of the Omatako and Omaruru rivers, together with their sampling sites shown as triangles (after Cigizoglu et al., 2002)

of the endorheic Okavango Basin, and the Omaruru flowing west to the Atlantic. The country has a subtropical desert climate, and ephemeral flow events in both rivers are generally confined to the wet season between January and April, which are also the hottest months. Mean daily flows for the Omatako River at Ousema are available for 29 years (1962-1990) and for the Omaruru at the town of Omaruru for 22 years (1965-1986).

In central Australia, in the large Lake Eyre Basin, flow data from two rivers, the Todd at Alice Springs and Cooper Creek at Cullyamurra have also been examined. The Lake Eyre Basin covers over 1.1 million $\mathrm{km}^{2}$ of the generally arid central zone of Australia, having the lowest mean annual runoff of any major drainage basin in the world (Kotwicki

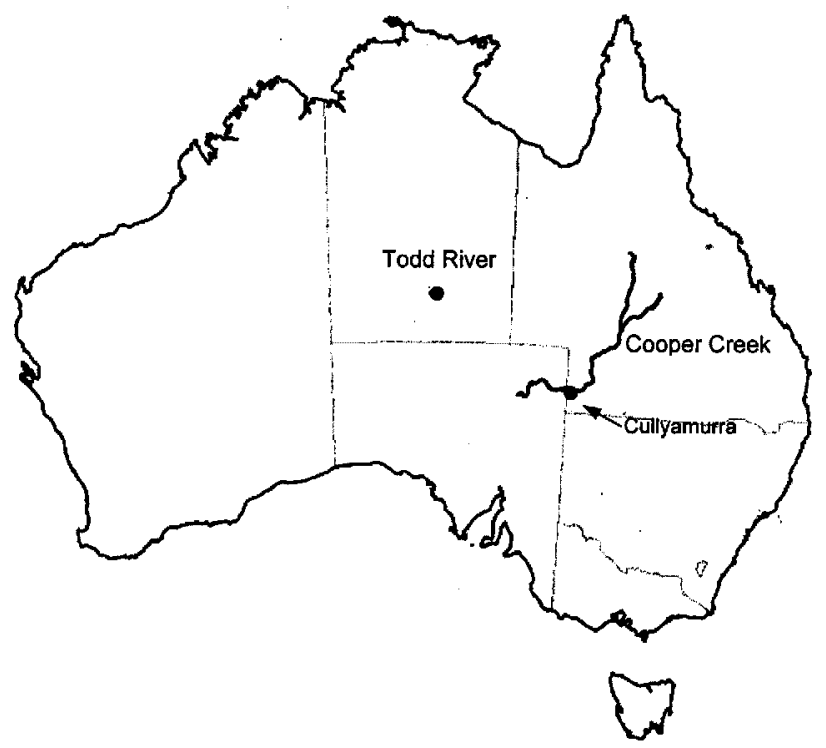

Fig. 2. Locations of Cooper Creek and Todd River in Australia

and Allan, 1998). Located at the north-western edge of this basin, in the geographical centre of the continent, the subcatchment of the Todd River above Alice Springs covers some $450 \mathrm{~km}^{2}$. The Cooper Creek sub-catchment, however, is considerably larger, approximately $306000 \mathrm{~km}^{2}$, most of which is located upstream of the observation point (Fig. 2). Both rivers display high variability in the duration and volume of their discharges. Daily flows are available for 37 years for the Todd (1962-1998) and for 29 years for the Cooper (1973-2001). In later models that incorporate climatic influences, flows in the Cooper recorded after 1998 are not used, to be consistent with the period of available IPO data.

All four rivers are characterised by periods of very little or no flow that separate distinct flow events. This feature is more pronounced in the Omatako and Omaruru, where such flow events have an average duration of 8.5 and 5.5 days respectively. In contrast, flows in the Todd continue for an average of 41 days, and the Cooper 155 days, most likely due to its large catchment size. In this study, flow events are referred to as 'spates', defined as a continuous sequence

Table 1. Summary flow statistics for the four rivers investigated

\begin{tabular}{|c|c|c|c|c|c|c|c|c|}
\hline \multirow[t]{2}{*}{ River } & \multirow{2}{*}{$\begin{array}{l}\text { Sample } \\
\text { (years) }\end{array}$} & \multirow{2}{*}{$\begin{array}{l}\text { Catchment } \\
\left(\mathrm{km}^{2}\right)\end{array}$} & \multicolumn{4}{|c|}{ Total annual flow $\left(x 10^{6} \mathrm{~m}^{3}\right)$} & \multicolumn{2}{|c|}{ Number of annual spates } \\
\hline & & & Minimum & Median & Mean & Maximum & Mean & Variance \\
\hline Omatako & 29 & 4970 & 1 & 20 & 35 & 144 & 4.45 & 5.61 \\
\hline Omaruru & 22 & 2520 & 0 & 23 & 28 & 110 & 2.59 & 4.54 \\
\hline Todd & 37 & 450 & 0 & 6 & 11 & 94 & 3.27 & 4.65 \\
\hline Cooper & 29 & 306000 & 21 & 392 & 1636 & 14360 & 1.66 & 0.88 \\
\hline
\end{tabular}




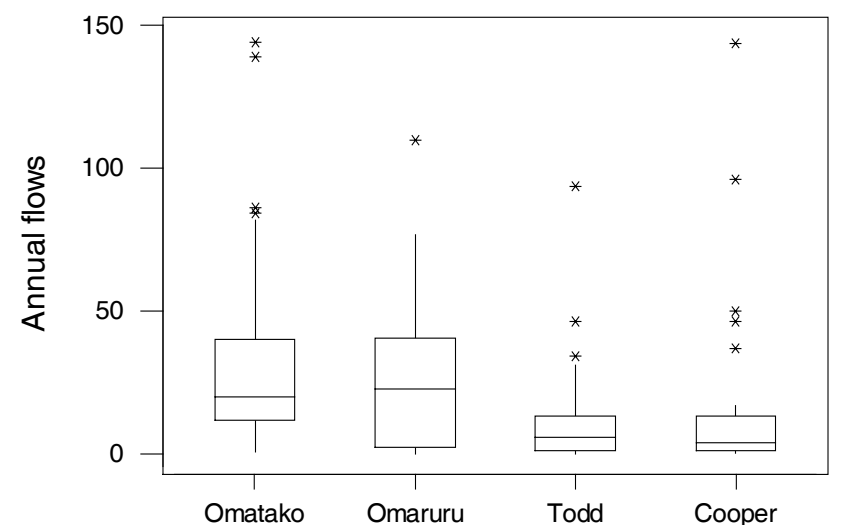

Fig. 3. Boxplots of annual flows in the Omatako, Omaruru and Todd (shown as $\times 10^{6} \mathrm{~m}^{3}$ ) and the Cooper $\left(x 10^{8} \mathrm{~m}^{3}\right)$, with asterisks showing outlying values beyond interquartile range

of days over which non-zero flow is recorded. Annual summary statistics of the flow records from the four rivers are presented in Table 1, with water years beginning October 1 st. Boxplots of the annual flow records of the four rivers, shown in Fig. 2, display the median and the interquartile (IQ) range between the first quartile (Q1) and third quartile (Q3). The whiskers shown on these plots extend from the IQ range to an upper limit (defined as 1.5(Q3-Q1)+Q3), and a lower limit (Q1-1.5(Q3-Q1)), with values outside these limits shown as asterisks. Daily flow exceeded the sample average on $9 \%$ of the time for the Cooper, $7 \%$ for the Omatako and 3\% for both the Todd and Omaruru. The distinctive patterns of flow in these rivers and the association between the two African rivers and also between the two Australian rivers are shown in Figs. 4 and 5 respectively, using two-year samples of daily flow.

' Variability in the ENSO signal is assessed through the MEI and IPO data. Kiem and Franks (2001) showed that the MEI outperformed the more traditional SOI and NINO3 indices in identifying ENSO-related changes in rainfall and runoff observations. The MEI can be used to classify ENSO events in various ways, including the approach of Chiew et al. (1998), who used mean index values over twelve-month periods from April to March to define both El Niño and La Niña phases. The method used in this study follows one of the approaches of Kiem and Franks (2001); they used averages of monthly index values over six-month periods from October to March to distinguish annual ENSO phases and claim that this method is the most robust for identifying ENSO variability over the time period being investigated. In this manner, El Niño years are characterised as any year in which the six-month MEI average beginning in the previous October is above 0.5 and La Niña events as years in which this average is below -0.5 . Six-month averages of
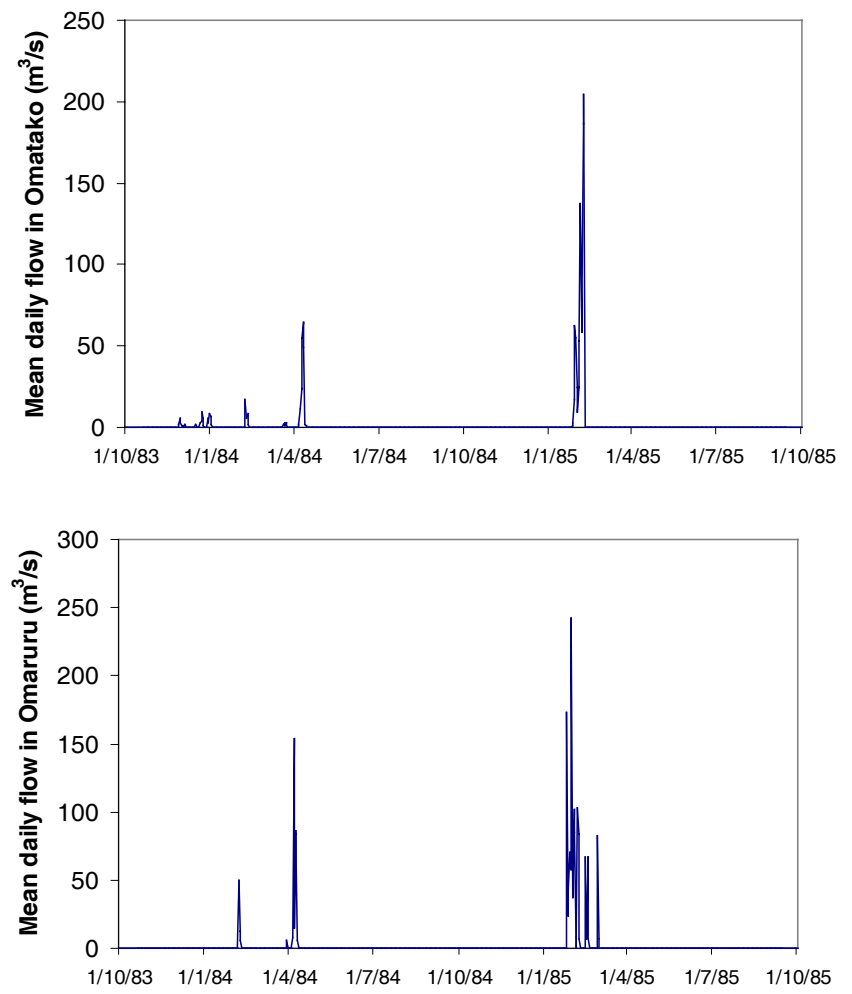

Fig. 4. A typical sequence of daily flows in the Omatako and Omaruru rivers (1983-1985)
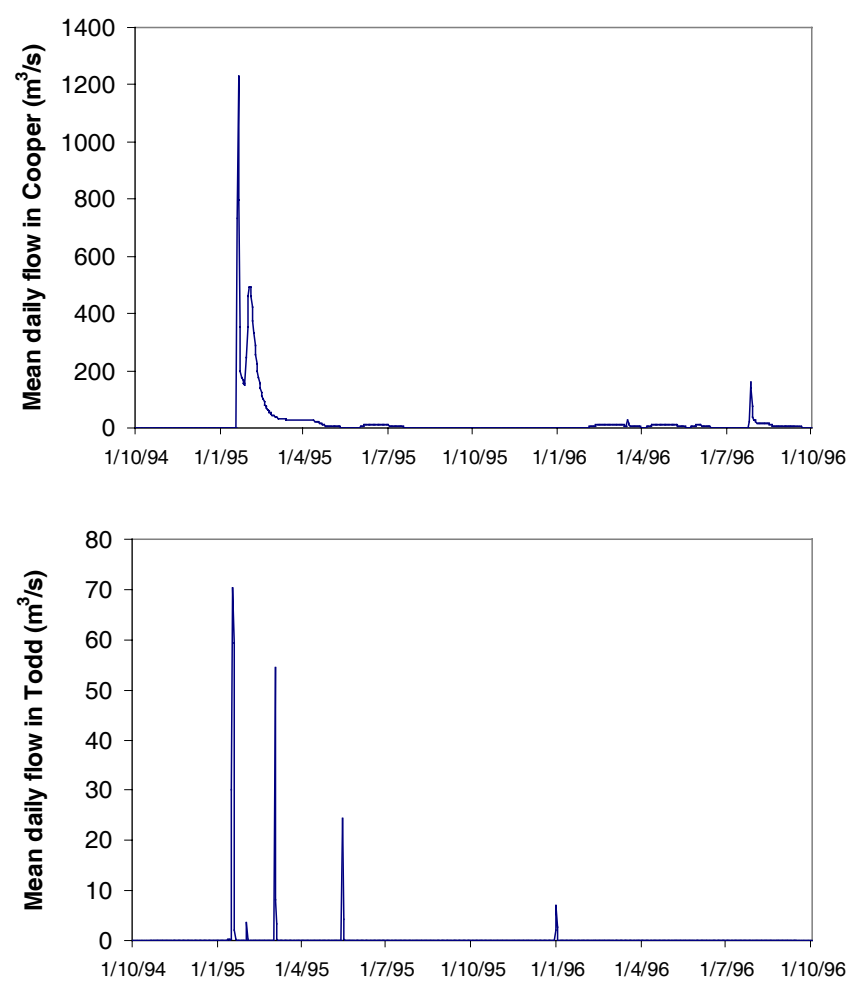

Fig. 5. A typical sequence of daily flows in Cooper Creek and the Todd River (1994-1996) 
the IPO, provided in seasonal totals, are also taken in this study.

\section{Modelling numbers of spate flows}

The first aspect of this investigation is to examine the influence of the ENSO signals on the record of spate flow numbers across the four rivers. If the underlying random processes can be considered the same from one year to the next, the annual spates would follow a Poisson distribution. The alternative considered is that the underlying processes depend on slowly varying global climate conditions that result in greater variability in the number of annual spates than are expected from a Poisson distribution. Flows in the Cooper tend to have longer durations because its catchment is considerably larger than those of the other rivers, hence fewer spates are observed at the observation point each year.

\section{POISSON REGRESSION MODELS}

Initially, interactions between ENSO and the number of observed flow episodes were modelled using a Poisson regression function, which includes explanatory variables such as the MEI and the IPO. In this model, it is assumed that the dependent variable $Y$ has a Poisson distribution given the independent variables $X_{1}, X_{2}, \ldots, X_{m^{\prime}}$, that is

$$
P\left(Y=k \mid X_{1}, X_{2}, \ldots, X_{m}\right)=\frac{e^{-\mu} \mu^{k}}{k !} \quad k=0,1,2, \ldots
$$

where $\mu$ is the mean of the Poisson process. The logarithm of this mean value is assumed to be a linear function of the explanatory variables, i.e.

$$
\ln (\mu)=\alpha_{0}+\alpha_{1} X_{1}+\alpha_{2} X_{2}+\ldots+\alpha_{m} X_{m}
$$

The choice of a logarithm as the link function to relate the mean of the process to its predictor variables has the result of ensuring fitted values of $\mu$ remain positive. The deviance is a measure of the variability of $Y$. If $Y$ has a Poisson distribution, the expected value of the deviance will equal the degrees of freedom, with a substantially larger value being evidence for $Y$ being over-dispersed. Therefore, a best model is selected on the basis of smallest deviance.
By using the average of climate index values over October to March periods as being indicative of annual conditions, the model with the lowest standard deviation of residuals from fitting these predictors to the Omatako record was the following:

$$
\ln (\mu)=1.456-0.284 \times M E I
$$

This equation, which was not improved by the inclusion of the IPO, produces a residual deviance of 26.96 on 27 degrees of freedom, consistent with the hypothesis of a Poisson variable. This can be compared with a residual deviance of 36.38 on 28 degrees of freedom for a null model without climate predictors, corresponding to an $\mathrm{R}^{2}$ of $25.9 \%$. Consequently, the regression of MEI averages (calculated from observations over six-month periods) on the number of Omatako spates can be regarded as a suitable fit, with this index alone being able to explain the excess variability in the Poisson-distributed response.

For the time series of annual spates in the Omaruru and Todd rivers, the MEI and IPO predictors are unable to explain sufficiently the excess variability in the records of annual spates, with residual deviance remaining in excess of the number of degrees of freedom. Although these index values failed to be significant indictors of spate flows in these rivers, ENSO impact can be identified through an alternative method. As stated earlier, six-month MEI averages classify each year as being in the El Niño, La Niña or neutral phase. The modulation of these ENSO phases by the interdecadal variability of the IPO can be exploited by using six-month averages of the IPO index also to categorise years as being in either IPO negative (IPO $<-0.5$ ), IPO neutral $(-0.5<\mathrm{IPO}<0.5)$ or IPO positive (IPO $>0.5)$ phases. The combination of both the ENSO and the IPO effects can then be incorporated into the nine climate categories that are shown in Table 2; these are then used to classify each year of observations. By considering the central category, which represents neutral IPO and neutral ENSO conditions as a base condition, eight indicator variables then categorise the other climate states. For each annual period, the category corresponding to the specific combination of MEI and IPO in that year takes a value of one, with each of the other seven variables taking a value of zero.

Table 2. Annual climate indicator categories based on MEI and IPO values

\begin{tabular}{lccc}
\hline & $I P O<-0.5$ & $-0.5<I P O<0.5$ & $I P O>0.5$ \\
\hline MEI $<-0.5$ (La Niña) & 1 & 8 & 7 \\
$-0.5<$ MEI $<0.5$ (Neutral) & 2 & 4 & 6 \\
MEI $>0.5$ (El Niño) & 3 & 4 & 5 \\
\hline
\end{tabular}


Table 3. Comparison of the optimum Poisson regression models for number of annual spates in the Omatako, Omaruru and Todd rivers using both six-month averages of MEI and IPO values as indicative of annual totals, and category indicator variables (shown in bold) as predictors

\begin{tabular}{|c|c|c|c|c|}
\hline River & $\begin{array}{l}\text { Best predictive models for } \ln (\mu) \\
\text { with standard errors of coefficients in brackets }\end{array}$ & Residual deviance & Degrees of freedom & $A I C$ \\
\hline \multirow[t]{2}{*}{ Omatako } & $\begin{array}{l}1.456-0.284 \times \mathrm{MEI} \\
(0.091)(0.094)\end{array}$ & 26.962 & 27 & 124.37 \\
\hline & $\begin{array}{l}1.585-1.026 \times \text { FIVE } \\
(0.091)(0.389)\end{array}$ & 26.834 & 27 & 124.24 \\
\hline \multirow[t]{2}{*}{ Omaruru } & $\begin{array}{l}0.935-0.259 \times \mathrm{MEI}+0.237 \times \mathrm{IPO} \\
(0.135)(0.154)(0.127)\end{array}$ & 38.241 & 19 & 95.87 \\
\hline & $\begin{array}{l}0.606+0.616 \times(\text { FOURorFIVEorSIX }) \\
(0.212)(0.272)\end{array}$ & 36.993 & 20 & 92.62 \\
\hline \multirow[t]{2}{*}{ Todd } & $\begin{array}{l}1.104+0.174 \times \mathrm{IPO} \\
(0.104)(0.088)\end{array}$ & 54.409 & 35 & 160.23 \\
\hline & $\begin{array}{l}1.317-1.066 \times(\text { ONEorTWO }) \\
(0.094)(0.345)\end{array}$ & 45.508 & 35 & 151.33 \\
\hline
\end{tabular}

Poisson regressions for the time series of spates in the Omatako, Omaruru and Todd are now fitted with the eight indicator series. Table 3 compares the best models for each river, using only the indices, and their interaction, as predictors, with the best models obtained from fitting the category indicators (shown in bold). The Akaike Information Criterion (AIC) (Akaike, 1974), which is a standard statistical criterion that penalises likelihoods based on numbers of fitted parameters, is used to compare the fit of each model, with better models having a lower AIC value. The results in this table show that category predictors can provide better regression models than those based solely on climate index predictors.

In the Omaruru, the best regression model on index values shown in Table 3 was not improved by the inclusion of the cross product of the MEI and IPO. The optimum model from fitting climate categories used one index that combined categories four, five and six. Categories four and five represent El Niño conditions, which is a similar result to that gained from the Omatako record. In the Todd, a regression of spates on the IPO was not improved by the MEI, yet is surpassed by a model using categories one and two. These categories represent La Niña conditions is IPO negative periods, a result that is consistent with observations made by Power et al. (1999) concerning the impact of this interdecadal modulation of ENSO impact across Australia. These results indicate that ENSO influence is responsible for most of the clustering of spates when these rivers are modelled as individual series.

\section{BIVARIATE POISSON MODELS}

A regional influence of ENSO upon isolated flows in these arid rivers will be more apparent if the observations from two rivers in the region are considered together. With the Omatako and Omaruru located in close vicinity (and similarly with the Todd and Cooper), both rivers will be under similar climatic influences and, thus, models of their spates may be improved by incorporating this common effect. A plausible model that allows for dependence within the two pairs of rivers is the bivariate Poisson distribution; this retains a Poisson assumption for the number of annual spates recorded in each of two rivers, together with dependence between flows in these rivers. This bivariate framework has been fitted to annual spates in the African rivers over their common period of 1965-1986, and to the Australian rivers over the period 1973-1998.

The bivariate distribution allows for dependence between the Poisson-distributed variables $Y_{1}$ and $Y_{2}$, which have the expected values $E\left(Y_{1}\right)=\mu_{1}=\left(\lambda_{1}+\lambda_{3}\right) \quad$ and $E\left(Y_{2}\right)=\mu_{2}=\left(\lambda_{2}+\lambda_{3}\right)$. The dependence between the variables is included in the model by the parameter $\lambda_{3}$, which is the covariance between $Y_{1}$ and $Y_{2}$. If $\lambda_{3}$ equals zero, the model reduces to the product of two independent Poisson distributions. The joint density of the bivariate Poisson distribution, as presented by Karlis and Ntzoufras (2003) is

$$
\begin{aligned}
P\left(Y_{1}=y_{1}, Y_{2}=y_{2}\right)= & e^{-\left(\lambda_{1}+\lambda_{2}+\lambda_{3}\right)} \frac{\lambda_{1}^{y_{1}} \frac{\lambda_{2}^{y_{2}}}{y_{1} !} y_{2} !}{\sum_{k=0}^{\min \left(y_{1}, y_{2}\right)}\left(\begin{array}{l}
y_{1} \\
k
\end{array}\right)\left(\begin{array}{l}
y_{2} \\
k
\end{array}\right) k !\left(\frac{\lambda_{3}}{\lambda_{1} \lambda_{2}}\right)^{k}}
\end{aligned}
$$

The influence of ENSO on the spate occurrence is 
incorporated in this bivariate model by allowing the natural logarithm of the expected number of observations in river $i$, $\ln \left(\mu_{\mathrm{i}}\right)$, to be a linear function of climatic predictors such as the category indicators, or six-month averages of the MEI and IPO as shown in Eqn. (5). This assumption is, thus, consistent with the univariate Poisson regression model of Eqn. (2):

$$
\ln \left(\mu_{i}\right)=\alpha_{0, i}+\alpha_{1, i} M E I+\alpha_{2, i} I P O \quad i=1,2
$$

The dependence parameter $\lambda_{3}$ is estimated by the covariance between the annual numbers of spates in the two rivers. The remaining parameters are then fitted by a method of maximum likelihood. Alternatively, the expectationmaximisation algorithm developed by Karlis and Ntzoufras (2003) could be used for parameter estimation. The Adaptive Metropolis algorithm (Haario et al., 2001), a Monte Carlo Markov Chain (MCMC) method, is employed to evaluate parameter uncertainty in the form of posterior distributions for the set of unknown parameters. These posteriors are important in the application of Bayesian model selection as a method of comparing the fit of a range of models to each pair of observations. Bayes Factors (BFs) are a useful implementation of Bayesian model selection, and the method of Gelfand and Dey (1994) is applied here, with the full posterior distributions being utilised in the relevant calculations. When presented with a range of models $\left(M_{i}: \mathrm{i}=0,1,2 ..\right)$, the BFs are ratios between the marginal likelihoods of each model, or

$$
B F_{1,0}=\frac{p\left(Y \mid M_{1}\right)}{p\left(Y \mid M_{0}\right)}
$$

High positive values of $B F_{1,0}$ indicate strong evidence that model $M_{1}$ is a better fit than $M_{0}$ to the series of observations, and vice versa for high negative values. Kass and Raftery (1995) provide scales for interpreting BF values, in terms of twice the value of the natural logarithm of the $\mathrm{BF}$, $2 \times \ln \left(B F_{1,0}\right)$, which is on the same scale as traditional likelihood ratio tests. Values of $2 \times \ln \left(B F_{1,0}\right)$ can then fall into the following categories of evidence against $M_{0} ; 0$ to 2 — 'weak', 2 to 6 — 'positive', 6 to 10 — 'strong', $>10$ 'very strong'.

The results from fitting bivariate Poisson models to both the Australian and African rivers are compared to those from independent models using BF analysis. The results in Table 4 show the best bivariate models from fitting ENSO indices, together with Bayes Factors from comparing these models to bivariate Poisson models with constant parameters. The model fitted to the Australian rivers was not improved by the addition of the MEI. Table 5 displays the results from the best models obtained from fitting climate categories rather than indices to these bivariate spate records. To maintain consistency with the results in Table 3, the category predictor for the Omatako and Omaruru combines categories four, five and six and the predictor for the Todd and Cooper combines categories one and two. The BF results in Table 5 are acquired from comparing climate category models to independent models and, with these being larger than BF totals in Table 4, it is apparent that the categories provide a

Table 4. Coefficients and standard errors (SE) for optimum bivariate Poisson models, using climate indices as predictor variables, together with Bayes Factors (BF) from comparing to fixed parameter models

\begin{tabular}{lllll}
\hline River & Constant (SE) & Coefficient of MEI (SE) & Coefficient of IPO (SE) & $2 \times \ln \left(B F_{1,0}\right)$ \\
\hline Omatako & $1.465(0.106)$ & $-0.214(0.111)$ & $-0.144(0.099)$ & 3.56 \\
Omaruru & $0.936(0.135)$ & $-0.266(0.150)$ & $0.234(0.126)$ & 2.59 \\
Todd & $0.860(0.192)$ & - & $0.332(0.149)$ & $-0.005(0.157)$ \\
Cooper & $0.502(0.190)$ & - & & - \\
\hline
\end{tabular}

Table 5. Coefficients and standard errors (SE) for optimum bivariate Poisson models, using climate categories as predictor variables, together with Bayes Factors (BF) from comparing to fixed parameter models

\begin{tabular}{llcll}
\hline River & Constant(SE) & $\begin{array}{l}\text { Coefficient of categories } \\
(1 \text { or 2) (SE) }\end{array}$ & $\begin{array}{l}\text { Coefficient of categories } \\
\text { (4 or 5 or 6) (SE) }\end{array}$ & $2 \times \ln \left(B F_{1, \theta}\right)$ \\
\hline Omatako & $1.660(0.125)$ & - & $-0.419(0.211)$ & 9.49 \\
Omaruru & $0.608(0.208)$ & - & $0.632(0.272)$ & 8.80 \\
Todd & $1.286(0.111)$ & $-1.197(0.850)$ & - & - \\
Cooper & $0.486(0.165)$ & $0.130(0.422)$ & - & \\
\hline
\end{tabular}


slightly improved description of spate flows than the climate indices. Therefore, models of bivariate flow patterns in both arid regions are improved by using indicators of ENSO variability and its multi-decadal modulation.

\section{Modelling total annual flows}

The second stage of this study is to identify whether the ENSO phases are related to total annual flows in each river. Having previously shown that these indices are related to the occurrence of discrete flow episodes in all four rivers, it is pertinent to investigate whether the total flows in each river are also influenced by similar climatic processes.

\section{MULTIPLE LINEAR REGRESSION}

The total variability attributed to the ENSO in the time series of annual flow of the four rivers is first analysed through regressing flows on the MEI and IPO. Table 6 gives the coefficients (with standard errors) for the regression models with the lowest standard deviation of residuals for flows (in quantities of $\left.1 \times 10^{6} \mathrm{~m}^{3}\right)$ in each river. For the Todd and Cooper, the addition of a (MEI $\times$ IPO) term improved the regression, reducing the standard deviation of residuals from 17.73 to 16.57 and from 2905 to 2674 respectively. The ENSO indices are shown to account for the least amount of variation in Omaruru flows, with its regression significant only at a P-value of 0.259 . The regression of Omaruru flows, however, was vastly improved by including the time series of annual numbers of spates as a predictor together with the ENSO indices; the standard deviation of residuals was reduced from 28.60 to $22.05, \mathrm{R}^{2}$ increased to $51.2 \%$ and the $\mathrm{P}$-value was reduced to 0.004 .

\section{REGRESSION OF BIVARIATE FLOW DATA}

With multiple linear regressions identifying the interrelationships between ENSO phases, interdecadal SST modulation in the Pacific and arid zone streamflows, the regional impact of these climatic processes can also be investigated. The bivariate Poisson model showed that by considering the observations from two rivers in a region together, modelling of the ENSO influence on arid flows could be enhanced. To examine whether a similar result is achieved with time series of annual flow volumes, bivariate distributions are used to describe the residuals from regression functions of flows in the Omatako and Omaruru, and the Todd and Cooper. The common periods of flow used in the bivariate Poisson modelling are also used here.

The natural logarithm of total annual flow in river $i, \ln \left(Y_{i}\right)$, is assumed to follow the relationship

$$
\ln \left(Y_{i}\right)=\alpha_{0, i}+\alpha_{1, i} \mathrm{MEI}+\alpha_{2, i} \mathrm{IPO}+\alpha_{3, i}(\mathrm{MEI} \times \mathrm{IPO})+E_{i}
$$

where the residuals $E_{i}$ are generated from a bivariate normal distribution. Equation 7 uses the MEI and IPO as predictors of annual flows in each river, together with the product of these indices, which takes into account the interaction of the MEI and IPO. Different coefficients for these predictors are estimated for flows in each of the two rivers. The natural logarithm of flows is used in Eqn. (7) to produce marginal residuals that more closely approximate a series of random draws from a normal distribution. Table 7 gives the coefficients of the best regression models from using combinations of the predictor variables in Eqn. (7), together with the estimated correlation of the errors. The best models are identified as those that produce the largest Bayes Factors

Table 6. Coefficients and standard errors (SE) for regression of annual flows against climate indices, with $\mathrm{R}^{2}$ values, standard deviation of residuals $(\mathrm{S})$ and overall $\mathrm{P}$-value

\begin{tabular}{|c|c|c|c|c|c|c|c|}
\hline River & $\begin{array}{l}\text { Constant } \\
(\mathrm{SE})\end{array}$ & $\begin{array}{l}\text { Coefficient of MEI } \\
\text { (SE) }\end{array}$ & $\begin{array}{l}\text { Coefficient of IPO } \\
(\mathrm{SE})\end{array}$ & $\begin{array}{l}\text { Coefficient of MEI } \times I P O \\
(\mathrm{SE})\end{array}$ & $R^{2}$ & $S$ & P-value \\
\hline Omatako & $\begin{array}{l}35.49 \\
(6.48)\end{array}$ & $\begin{array}{l}-17.43 \\
(6.53)\end{array}$ & - & - & $20.9 \%$ & 34.89 & 0.013 \\
\hline Omaruru & $\begin{array}{l}28.63 \\
(6.12)\end{array}$ & $\begin{array}{l}-9.46 \\
(6.42)\end{array}$ & $\begin{array}{c}8.06 \\
(5.86)\end{array}$ & - & $13.3 \%$ & 28.60 & 0.259 \\
\hline Todd & $\begin{array}{l}9.80 \\
(2.96)\end{array}$ & $\begin{array}{l}-2.62 \\
(2.85)\end{array}$ & $\begin{array}{l}-2.93 \\
(2.64)\end{array}$ & $\begin{array}{c}6.64 \\
(2.27)\end{array}$ & $24.3 \%$ & 16.02 & 0.025 \\
\hline Cooper & $\begin{array}{l}1533.5 \\
(918.7)\end{array}$ & $\begin{array}{l}-1986.4 \\
(743.7)\end{array}$ & $\begin{array}{c}-354.8 \\
(745.7)\end{array}$ & $\begin{array}{l}1317.4 \\
(580.2)\end{array}$ & $44.1 \%$ & 2674 & 0.004 \\
\hline
\end{tabular}

Correlation of residuals for Omatako and Omaruru over the period $(1965-1986)$ is $0.568(\mathrm{p}=0.006)$ and the correlation of residuals for Cooper and Todd over the period (1973-1998) is $0.475(\mathrm{p}=0.014)$ 
Table 7. Coefficients and standard errors (SE) for optimum regression models of bivariate flow records, with bivariate normal distributions fitted to residuals from each pair of rivers

\begin{tabular}{llllll}
\hline River & Correlation & $\begin{array}{l}\text { Constant } \\
(\mathrm{SE})\end{array}$ & $\begin{array}{l}\text { Coefficient of MEI } \\
(\mathrm{SE})\end{array}$ & $\begin{array}{l}\text { Coefficient ofIPO } \\
(\mathrm{SE})\end{array}$ & $\begin{array}{l}\text { Coefficient of MEI } \times \text { IPO } \\
(\mathrm{SE})\end{array}$ \\
\hline $\begin{array}{l}\text { Omatako } \\
\text { Omaruru }\end{array}$ & 0.785 & 11.300 & -0.458 & -0.309 & - \\
Todd & $(0.105)$ & $(5.740)$ & $(0.221)$ & $(0.207)$ & - \\
Cooper & 0.326 & 11.032 & -0.674 & $0.198(0.448)$ & 0.466 \\
\hline
\end{tabular}

when compared to bivariate models in which the ENSO indices have no influence on annual flows (in which case the two flow series are approximated by a standard bivariate normal distribution).

As shown in Table 7, the best regression model for the African rivers included values for $\alpha_{0}, \alpha_{1}$ and $\alpha_{2}$ that were equal for each of the two rivers, and was not improved by the addition of an (MEI $\times$ IPO) term. This model form produced a $2 \times \ln \left(B F_{1,0}\right)$ value of 10.68 when compared to a standard bivariate normal distribution on the logarithm of flows. The best model for the Cooper and Todd also included values for $\alpha_{0}, \alpha_{1}$ and $\alpha_{3}$ that were equal for the two rivers, and values for $\alpha_{2}$ that were fitted separately for flows in each river. This model produced a $2 \times 1 \mathrm{n}\left(B F_{1,0}\right)$ value of 7.89 .

The results in Tables 6 and 7 demonstrate that ENSO processes influence annual flow volumes in the arid zone rivers studied here. Although the characteristics of flow vary dramatically across these rivers, with the Omatako and Omaruru showing much shorter flow episodes and longer dry periods between such episodes, ENSO phases explain a large amount of flow variability in each river. Furthermore, with the bivariate analysis providing an improved description of the relationship between streamflow and climate processes, it is evident that the regional extent of the ENSO phases is an important feature.

\section{Conclusions}

This study has concentrated on the linkage between the quasi-periodic El Niño/Southern Oscillation (ENSO), its potential modulation by the Interdecadal Pacific Oscillation (IPO) and the multivariate hydrological response in arid regions. In particular, it has shown a teleconnection between the rate of occurrence, and volume of, short flow episodes (spates) in two disparate southern hemisphere arid regions and ENSO with IPO. These associations have been incorporated into multivariate stochastic models that could be applied to streamflow data from other arid areas.
The combined influence of ENSO and IPO is modelled either by linear terms in these two variables and their interaction or by indicator variables for nine broad climate categories, and is demonstrated to be statistically significant despite relatively short records. The use of categories gave a slightly better fit to the models for occurrences of spates. Since the dominant climate category influencing spate occurrences in the Todd and Cooper corresponds to La Niña/ IPO negative periods, the results of this study supported those of Power et al. (1999) for rainfall. Such results suggest that the influence of ENSO and the IPO on spate occurrences is non-linear. In contrast, the influence of ENSO and the IPO on volumes is rather better modelled as linear in the MEI and the IPO indices and possibly their product, representing their interaction.

Power et al. (1999), amongst others, have demonstrated a linkage between ENSO, IPO and rainfall. Kiem et al. (2003) and Kiem and Franks (2004) demonstrated a link with flooding and drought risk respectively. The results from the present study show similar relationships, for the frequency and volume of spates that provide the water resources for arid regions. The relationship appears to be stronger than that with point or spatially averaged rainfall. Realistic models for multivariate prediction of spate characteristics are required for flow prediction up to one year ahead, and for longer-term simulations that can direct the management of these resources in terms of water storage and economic development. With streamflow representing the complex integration of climatic and landscape responses that arguable amplify ENSO effects, a practical method for forecasting available water resources is to provide hydrological models with ENSO input.

Ghil and Jiang (1998) showed that recent progress in understanding the dynamics of ENSO has produced techniques that have useful forecasting skill over periods of up to 12 months. ENSO prediction techniques include dynamical approaches such as the use of general circulation models (GCMs) and purely statistical approaches such as the use of canonical correlation analysis (Barnston and 
Ropelewski, 1992). Ghil and Jiang (1998) showed the predictive skill for both dynamical and statistical approaches to be comparable, and forecasts of SSTs over the NINO3 regions can achieve a correlation skill against observed anomalies of up to 0.75 (Barnston et al., 1994). More recently, Berliner et al. (2000) used Bayesian dynamic modelling for predictions of Pacific SSTs at lead times of up to seven months, achieving comparable results to larger deterministic models. Also, Ghil et al. (2002) showed that the combination of singular spectrum analysis (SSA) with the maximum entropy method (MEM) of spectral analysis provides a robust method of predicting the doubly periodic variability of ENSO.

The relationship between ENSO variability and hydrological responses is almost always stronger than its relationship to rainfall (Chiew and McMahon, 2003). In focusing upon the highly variable arid regions of Australia and southern Africa, this paper concentrates upon hydroclimatic variables that demonstrate the most detectable response to ENSO modulation. Moreover, the statistical methods used in this analysis maximise the utility of the available hydrological data in arid zones by integrating the various facets of the hydrology in space and time. With the results of the current study showing both the rate of occurrence and the volume of short flow episodes in these rivers to be influenced by ENSO variability, the incorporation of ENSO and IPO predictors could potentially improve existing hydrological models.

\section{Acknowledgements}

This project was supported by an Australian Research Council Discovery grant.

\section{References}

Akaike, H., 1974. A new look at the statistical model identification. IEEE transactions on automatic control AC-19, 716-723.

Barnston, A.G. and Ropelewski, C.F., 1992. Prediction of ENSO episodes using canonical correlation analysis. J. Climate, 5, 1316-1345.

Barnston, A.G., van den Hool, H., Zebiak, S.E., Barnett, T.P., Ji, M., Rodenhuis, D., Cane, M.A.,Leetmaa, A., Graham, N.E., Ropelewski, C.F., Kousky, V.,O'Lenic, E. and Livezey, T.,1994. Long-lead seasonal forecasts - Where do we stand? Bull. Amer. Meteorol. Soc., 75, 2097-2114.

Berliner, L.M., Wilke, C.K. and Cressie, N., 2000. Long-Lead Prediction of Pacific SSTs via Bayesian Dynamic Modelling. J. Climate, 13, 3953-3968.

Chiew, F.H.S. and McMahon, T.A., 2003. El Nino/ Southern Oscillation and Australian rainfall and streamflow. Aust. J. Water Resour., 6, 115-129.
Chiew, F.H.S., Piechota, T.C., Dracup, J.A. and McMahon, T.A., 1998. El Nino/Southern Oscillation and Australian rainfall, streamflow and drought: Links and potential for forecasting. $J$. Hydrol., 204, 138-149.

Cigizoglu, H.K., Adamson, P.T. and Metcalfe, A.V., 2002. Bivariate stochastic modelling of ephemeral streamflow. Hydrol. Process., 16, 1451-1465.

Folland, C.K., Parker, D.E., Colman, A.W. and Washington, R., 1998. Large-scale modes of ocean surface temperature since the late nineteenth century (CRTN 81), UK Meteorological Office.

Folland, C.K., Renwick, J.A., Salinger, M.J. and Mullan, A.B., 2002. Relative influences of the Interdecadal Pacific Oscillation and ENSO on the South Pacific Convergence Zone. Geophys. Res. Lett., 29(13), doi: 1029/2001GL014201.

Franks, S.W., 2004. Multi-decadal climate variability, New South Wales, Australia. Water Sci., Technol., 49, 133-140.

Gelfand, A.E. and Dey, D.K., 1994. Bayesian Model Choice: Asymptotics and Exact Calculations. J. Roy. Statist. Soc., Ser. $B, \mathbf{5 6}, 501-514$.

Gershunov, A. and Barnett, T.P., 1998. Interdecadal modulations of ENSO teleconnections. Bull. Amer. Meteorol. Soc., 79, 27152725 .

Ghil, M. and N. Jiang, 1998. Recent forecast skill for the El Nino/ Southern Oscillation. Geophys. Res.Lett., 25, 171-174.

Ghil, M., Allen, M.R., Dettinger, M.D., Ide, K., Kondrashov, D., Mann, M.E., Robertson, A.W., Saunders, A., Tian, Y., Varadi F. and Yiou, P., 2002. Advanced spectral methods for climatic time series. Rev. Geophys., 40, 1003, doi:10.1029/2000RG000092.

Haario, H., Saksman, E. and Tamminen, J., 2001. An adaptive Metropolis algorithm. Bernoulli, 7, 223-242.

Jury, M.R. and Courtney, S., 1995. Climatic determinants of Benguela SST variability. Cont. Shelf Res., 15, 1339-1354.

Kaplan, A., Cane, M.A., Kushnir, Y., Clement, A.C., Blumenthal, M.B. and Rajagoplan, B., 1998. Analyses of global sea surface temperature 1856-1991. J. Geophys. Res., 103, 18567-18589.

Karlis, D. and Ntzoufras, I., 2003. Analysis of sports data by using bivariate Poisson models. Statist., 52, 381-393.

Kass, R.E. and Raftery, A.E., 1995. Bayes Factors. J. Amer. Statist. Assoc., 90, 773-795.

Kiem, A.S. and Franks, S.W., 2001. On the identification of ENSOinduced rainfall and runoff variability: a comparison of methods and indices. Hydrolog. Sci. J., 46, 715-727.

Kiem, A.S. and Franks, S.W., 2004. Multidecadal variability of drought risk, eastern Australia. Hydrolog. Process., 18, 20392050.

Kiem, A S., Franks, S.W. and Kuczera, G. A., 2003. Multi-decadal variability of flood risk. Geophys. Res. Lett,. 30(2), 1035 doi: 10.1029/2002GL015992.

Knighton, A.D. and Nanson, G.C., 2001. An event-based approach to the hydrology of arid zone rivers in the Channel Country of Australia. J. Hydrol., 254, 102-123.

Kotwicki, V. and Allan, R.J., 1998. La Nina de Australia contemporary and palaeo-hydrology of Lake Eyre. Palaeogeogr., Palaeoclimatol. Palaeoecol. 144, 265-280.

Landman, W.A. and Mason, S.J., 1999. Change in the association between Indian Ocean sea-surface temperatures and summer rainfall over South Africa and Namibia. Int. J. Climatol. 19, $1477-1492$.

Lindesay, J.A., 1988. South African rainfall, the Southern Oscillation and a southern hemisphere semi-annual cycle. $J$. Climatol., 8, 17-30.

Mantua, N., Hare, S.R., Zhang, Y., Wallace. J.M. and Francis, R.C., 1997. A Pacific interdecadal climate oscillation with impacts on salmon production. Bull. Amer. Meteorol. Soc., 78, 1069-1079. 
Mason, S.J., 1997. Recent Changes in El Nino - Southern Oscillation Events and their Implications for Southern African Climate. Trans. Roy. Soc. S. Afr., 52, 377-403.

Mason, S.J., 2001. El Nino, climate change, and Southern African climate. Environmetrics 12, 327-345.

Mason, S J. and Jury, M.R., 1997. Climatic variability and change over southern Africa: a reflection on underlying processes. Prog. Phys.Geogr., 21, 23-50.

McMahon, T.A., Finlayson, B.L., Haines, A.T. and Srikanthan, R., 1992. Global Runoff - Continental Comparisons of Annual Flows and Peak Discharges. Cremlingen, Catena Verlag.

Power, S., Casey, T., Folland, C., Colman, A. and Mehta, V., 1999. Inter-decadal modulation of the impact of ENSO on Australia. Clim. Dynam., 15, 319-324.
Puckridge, J.T., K.F. Walker and J.F. Costelloe, 2000. Hydrological Persistence and the Ecology of Dryland Rivers. Regul. River. 16, 385-402.

Ropelewski, C. F. and M. S. Halpert, 1987. Global and Regional Scale Precipitation Patterns Associated with the El Nino/ Southern Oscillation. Mon, Weather Rev., 115, 1606-1626.

Salinger, M. J., J. A. Renwick and A. B. Mullan, 2001. Interdecadal Pacific Oscillation and South Pacific Climate. Int. J.Climatol., 21, 1705-1721.

Troup, A. J., 1965. The Southern Oscillation. Quart. J. Roy. Meteorol. Soc., 91, 490-506.

Wolter, K. and M. S. Timlin, 1998. Measuring the strength of ENSO - how does 1997/98 rank? Weather 53, 315-324. 